\title{
Implementation Assistance Driver System for Public Transportation Based on Embedded System
}

\author{
A. Sumarudin ${ }^{1)}$, A. Suheryadi ${ }^{1}$, A. Puspaningrum ${ }^{1)}$, E. Prasetyo ${ }^{1)}$, Y.N Azis ${ }^{1)}$ \\ ${ }^{1)}$ Department of Informatics, Politeknik Negeri Indramayu, \\ Jl. Lohbener Lama No. 08 Lohbener Indramayu 45252 \\ shumaru@polindra.ac.id
}

(Article History： Received 07-04-2020; Accepted 21-05-2020; Published 07-06-2020)

\begin{abstract}
According to data from the World Health Organization (WHO) per year around 1.35 million people die as a result of traffic accidents. Therefore, one solution is the development of Smart Transportation, namely the implementation of the Advanced Driver Assistant System (ADAS) on public transportation. The purpose of this study is to provide a level of safety in public transportation in the form of providing recommendations in driving. ADAS is implanted in an Odroid device and then installed on public transportation. The system can provide speed recommendations, predict vehicle conditions whether safe or dangerous, and detect traffic signs. In its implementation the system provides speed recommendations using Artificial Intelligence (AI) which is the fuzzy logic method and to predict the condition of the vehicle using machine learning that is the Support Vector Machine method. The system output in the form of speed recommendations, vehicle safety predictions and traffic signs detection will be directly accepted by the driver both visually and soundly. From the test results, the system has an accuracy rate of $95.25 \%$ in predicting vehicle conditions.
\end{abstract}

Keywords: Assistance driver system; artificial intelligent; embedded device; machine learning; odroid

\section{Impelementasi Assistance Driver System untuk Transportasi Publik Berbasis Sistem Embedded}

\begin{abstract}
ABSTRAK
Menurut data dari organisasi kesehatan dunia (WHO) per tahun sekitar 1,35 juta orang meninggal akibat kecelakaan lalu lintas. Salah satu solusinya adalah pengembangan smart transport, yaitu penerapan advanced driver assistant system (ADAS) pada angkutan umum. Tujuan penelitian ini memberikan tingkat keselamatan pada transportasi publik berupa pemberian rekomendasi dalam berkendaraan. ADAS ditanamkan dalam perangkat odroid dan kemudian dipasang pada transportasi umum. Sistem ini dapat memberikan rekomendasi kecepatan, memprediksi kondisi kendaraan apakah aman atau berbahaya, dan mendeteksi rambu-rambu lalu lintas. Dalam implementasinya sistem memberikan rekomendasi kecepatan menggunakan artificial intelligence (AI) yang merupakan metode logika fuzzy dan untuk memprediksi kondisi kendaraan menggunakan pembelajaran mesin yaitu metode support vector machine. Output sistem dalam bentuk rekomendasi kecepatan, prediksi keselamatan kendaraan dan deteksi rambu lalu lintas akan langsung diterima oleh pengemudi baik secara visual maupun suara. Dari hasil pengujian, sistem memiliki tingkat akurasi 95,25\% dalam memprediksi kondisi kendaraan.
\end{abstract}

Kata kunci: Assitance driver system; inteligensi buatan; perangkat tertanam; pembelajaran mesin; odroid

\section{PENDAHULUAN}

Menurut data dari Organisasi Kesehatan Dunia (WHO) yang dikutip dari channelnewsasia.com (12/12/2018), sekitar
1,35 juta orang meninggal akibat kecelakaan lalu lintas setiap tahun. Menurut data ini itu berarti bahwa setiap 24 detik ada nyawa yang hilang karena kecelakaan lalu lintas. Beberapa 
penyebab kecelakaan termasuk pengemudi ngebut, mengemudi dalam kondisi mengantuk atau mabuk, kondisi kendaraan yang tidak standar, kondisi jalan yang berlubang, hingga terganggu oleh pengguna jalan lain seperti pejalan kaki atau sesama pengendara lainnya, dan banyak faktor lainnya. Dalam konsep kota cerdas yang dijelaskan oleh (Caragliu, et al., 2011; Gori, et al., 2015; Saunders, et al., 2015), menerangkan penyebaran konektivitas dan teknologi baru dalam pengembangan inovasi, tentunya diperlukan dalam memberikan solusi untuk problematika masyarakat. Oleh karena itu, peran konsep Kota Cerdas harus diterapkan pada sektor transportasi dengan mengembangkan Transportasi Cerdas.

Salah satu solusi untuk pengembangan smart transport adalah aplikasi asisstant driver, yang bertujuan untuk meningkatkan kinerja pengemudi dan meningkatkan keselamatan berkendara. Saat ini, beberapa produk kendaraan dilengkapi dengan berbagai asisstant drivers, seperti: anti-lock braking system (ABS) untuk meningkatkan keselamatan saat berkendara. Pada pengembangan lebih lanjut atau sering disebut advanced driver-assistance system (ADAS), rain sensor, lane centering recognition, Pengenal rambu lalu lintas, bantuan Lane Lane, Night Vision, Asisten pengemudi darurat, dan masih banyak lagi yang diterapkan (Park et al., 2018; Iranmanesh, et al., 2018; Mukhtar, Xia, \& Tang, 2015.

Penelitian yang dikembangankan terkait advanced driver-assistance system (ADAS) maupun autonomous cars mengarah pada mendeteksi kecelakan yang dalami oleh pengemudi. Tian, et al., 2018, dalam paper ini dirancang suatu metode untuk mendeteksi potensi kecelakan dari pengamatan perubahan pada lingkungan seperti hujan, kabut, kondisi pencahayaan secara otomatis. Metode yang digunakan dalam altikel tersebut adalah DNN (deep neural network) yang memungkinkan melakukan deep test untuk menentukan prilaku pengemudi yang salah dalam menghadapi kondisi lingkungan yang ada. Adapun penelitian berkenaan dengan neural network dapat di lihat pada (Bengio, et al., 2007; Karpathy, 2017; Krizhevsky, et al., 2012). Penelitian berkaitan dengan advanced driver-sssistance system (ADAS) maupun autonomous car dikembangkan dengan berbagai metode machine learning (Mitchell \& Others, 1997).

Dalam makalah ini kami mengusulkan sistem pendukung pengemudi atau asisten pengemudi yang akan diimplementasikan pada angkutan umum. Hal ini dikarenakan salah satu masalah kota adalah transportasi yang dirasa kurang aman dan nyaman. Dengan menanamkan perangkat dalam angkutan umum, sistem akan bekerja dengan memberi peringatan rambu-rambu lalu lintas, merekomendasikan kecepatan dan jarak aman ke kendaraan di dekatnya (Organization \& Others, 2017). Sistem ini diharapkan dapat membantu meningkatkan kinerja pengemudi angkutan umum sehingga memberikan keamanan dan kenyamanan bagi penumpang angkutan umum.

\section{METODE PENELITIAN}

Dalam sistem yang dibangun, kami menggunakan komponen, yaitu: lidar sensor, GPS, arduino, camera, odroid, LCD dan speaker (Gambar 1).

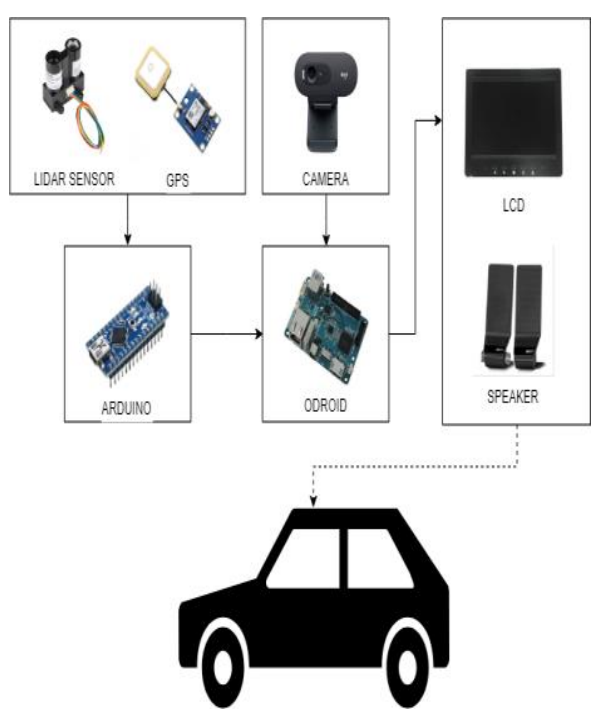

Gambar 1. Sistem Arsistektur

Secara bagan dapat ditunjukan pada gambar 2.

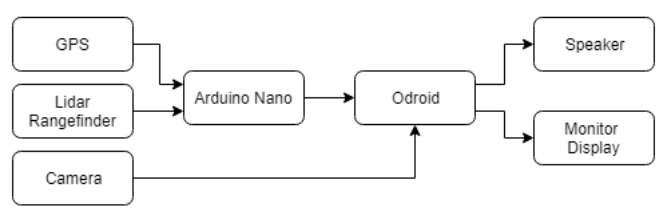

Gambar 2. Blok Sistem 
Berdasarkan Gambar 2, Arduino Nano digunakan untuk membaca data dalam bentuk kecepatan, bujur, dan lintang melalui perangkat GPS. Selain itu, Arduino juga membaca data jarak melalui Lidar. Setelah itu, keempat data dikirim ke Android melalui komunikasi serial. Kemudian odroid digunakan untuk mengakses kamera dan menjalankan program utama untuk menghasilkan output visual yang akan ditampilkan pada monitor dan audio melalui speaker. Sistem control yang dibangun menggunakan SVM untuk pengambilan keputusan dari input rambu dan sensor yang ada (gambar 3). Metode SVM banyak digunakan dalam dalam mengklasifikasikan prilaku pengemudi salah satunya penelitian yang dilakukan oleh Park, et al., 2017.

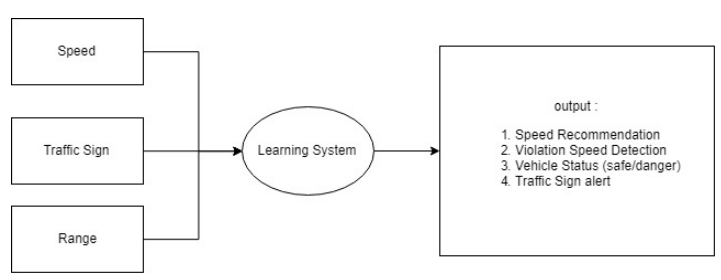

Gambar 3. Sistem Blok

Dalam sistem ini ada beberapa proses, yaitu Baca Tanda yang digunakan untuk menentukan input dalam bentuk rambu jalan yang dikenal. Kemudian proses membaca jarak akan menentukan input dalam bentuk jarak kendaraan di sekitar. Sedangkan Read Speed digunakan untuk menentukan input dalam bentuk kecepatan kendaraan. Dari ketiga parameter tersebut akan diproses menggunakan machine learning yang tertanam di ODROID untuk menghasilkan output berupa rekomendasi kecepatan, status kendaraan (Aman / Berbahaya), peringatan rambu-rambu lalu lintas, dan deteksi pelanggaran kecepatan jalan.

Data bersumber dari situs web archive.ics.uci.edu. Situs web ini telah menyediakan 476 set data yang digunakan untuk membantu komunitas pembelajaran mesin. File data yang digunakan memiliki format CSV. Data dipisahkan menggunakan koma (,). Contoh bentuk data yang digunakan dapat dilihat gambar 4 .
Id, speed, distance, period, warning, label1, lng, lat, warning_value, label2 $1,83,40,0,1,1,108.274097,-6.414626,60,0$ $3,25,15,0,1,0,-6.182732,108.837492,60,0$ $4,30,20,0,1,0,-6.182732,108.837492,60,0$ $5,45,35,0,1, \theta,-6.182732,108.837492,60, \theta$ $6,50,40,0,1, \theta,-6.182732,108.837492,60,0$ $7,55,45,0,1,0,-6.182732,108.837492,60,0$ $8,60,50,0,1,0,-6.182732,108.837492,60,0$

Gambar 4. Dataset

Tabel 1. kecepatan berkendaraan

\begin{tabular}{ccc}
\hline $\begin{array}{c}\text { Kecepatan } \\
(\mathrm{km} / \mathrm{jam})\end{array}$ & \multicolumn{2}{c}{ Jarak $(\mathrm{m})$} \\
\cline { 2 - 3 } & Minimum & Maksimum \\
\hline 30 & 15 & 30 \\
40 & 20 & 40 \\
50 & 25 & 50 \\
60 & 30 & 60 \\
70 & 35 & 70 \\
80 & 40 & 80 \\
90 & 45 & 90 \\
\hline
\end{tabular}

Dalam penelitian ini, menambahkan label secara manual, yaitu label pelanggaran untuk mempertimbangkan apakah kendaraan melanggar rambu-rambu lalu lintas terutama rambu-rambu kecepatan. Label ini mencakup dua kelas yaitu "Breaking" atau "Not Breaking" dengan membandingkan kecepatan aktual dengan batas kecepatan minimum atau maksimum jalan (tabel 1).

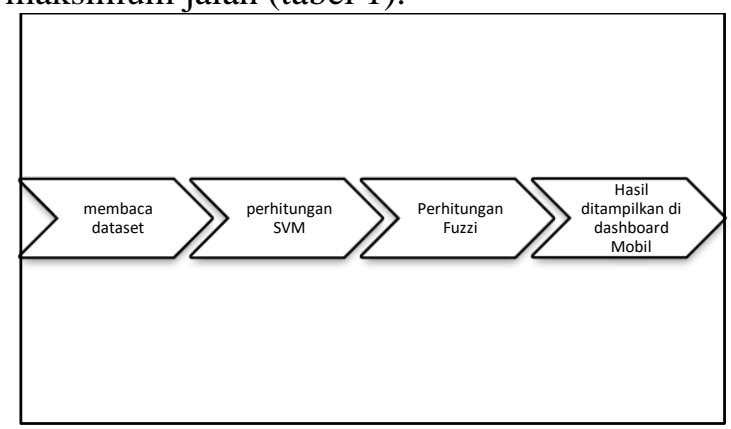

Gambar 5. Diagram Alir Sistem

Sistem dimulai dengan proses membaca baris data. Baris data ini adalah parameter yang digunakan dalam proses pembelajaran (SVM dan logika fuzzy). Jika garis data tersedia dalam dataset sistem, itu akan langsung memasuki proses logika fuzzy. Jika jalur data tidak tersedia, itu akan memasuki proses SVM. Setelah proses svm selesai maka akan dilanjutkan dengan proses logika fuzzy. Setelah proses fuzzy selesai, hasil dari proses akan ditampilkan di dashboard.

Dari proses rowData baca, ada parameter yang akan diperlukan dalam proses selanjutnya. Parameternya dalam bentuk 
daftar yang terdiri dari kecepatan, jarak, periode, peringatan, nilai peringatan, lintang dan bujur.

Proses SVM adalah proses mendapatkan label dalam bentuk nilai 0 dan 1 , di mana 0 berarti "AMAN" dan 1 berarti "BERBAHAYA". Selain itu, proses ini juga menentukan apakah kendaraan telah melanggar tanda kecepatan (nilai 1) atau tidak (0). Dalam proses ini membutuhkan 4 parameter, yaitu kecepatan, jarak, periode, dan peringatan. Proses ini menggunakan metode Mesin Vector Support untuk memprediksi apakah itu milik label "AMAN atau BAHAYA" dan apakah "Melanggar atau Tidak Melanggar".

Dalam proses fuzzy logic, ini digunakan untuk mendapatkan rekomendasi kecepatan aman dalam berkendara. Ini dapat dilihat melalui nilai parameter kecepatan dan jarak. Pada proses terakhir yaitu proses menampilkan hasil pada dashboard yang menampilkan hasil proses fuzzy dan SVM ke layar monitor odroid sehingga pengemudi dapat menerima rekomendasi yang dibuat oleh sistem. Dasar metode dalam pendeteksian dan rekomendiasi keamaan mengemudi telah dipaparkan dapa penelitian sebelumnya (Puspaningrum, et al., 2019).

\section{HASIL DAN PEMBAHASAN}

Berikut hasil implementasi dari sistem asisten pengendara, Antarmuka yang dibuat hanya untuk menampilkan hasil sistem sehingga dapat dilihat dan dipahami oleh pengemudi. Dalam aplikasi ini hanya ada 2 tampilan yaitu antarmuka dasbor dan antarmuka data pelanggaran.

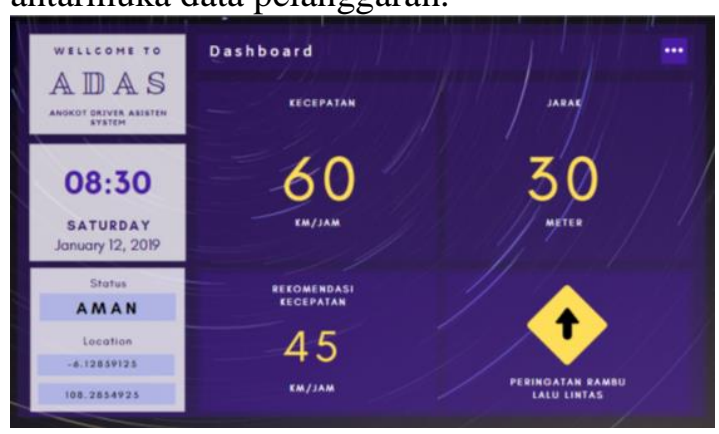

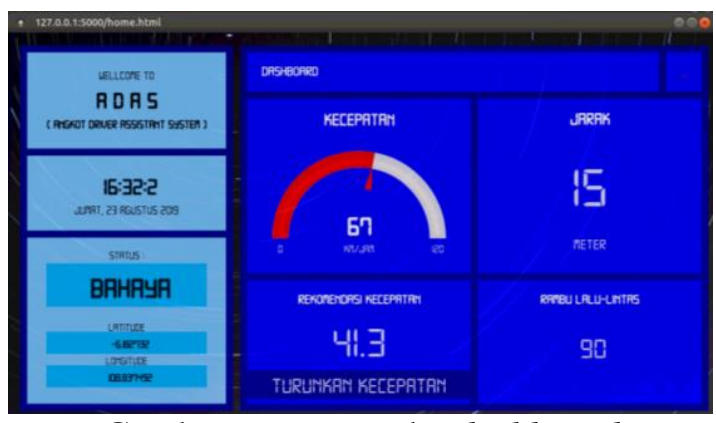

Gambar 6. antar muka dashboard

Tampilan dasbor di mana ada beberapa informasi termasuk info aplikasi (1), info waktu (2), informasi status keselamatan kendaraan dan status lokasi (3). Selain itu, ada info kecepatan aktual (4), info jarak aktual (5), info rambu lalu lintas (6), dan info kecepatan dan rekomendasi tindakan pengemudi. Berdasarkan desain pada gambar 6, perangkat embedded yang dibuat seperti pada gambar 7 .

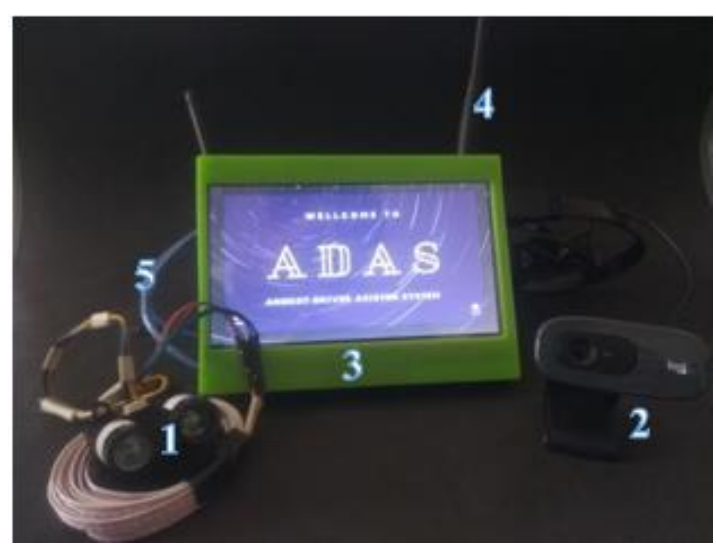

Gambar 7. sistem implementasi

Pada Gambar 7 ada beberapa komponen seperti sensor Lidar (1), Kamera (2), LCD (3), antena GPS (4), dan kabel komunikasi Arduino dan Odroid (5).

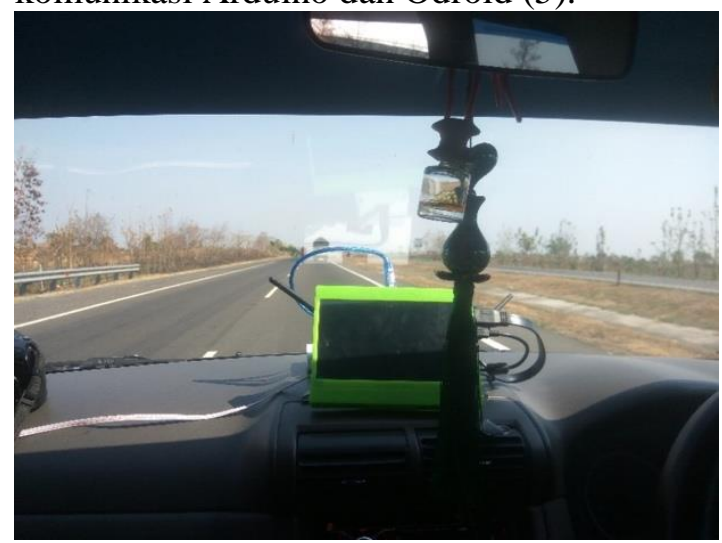

Gambar 8. implementasi saat mengemudi

Sensor Lidar dipasang di depan mobil. Sementara komponen lain dipasang di 
dashboard mobil atau angkutan umum (gambar 8).

Untuk menguji hasil prediksi keselamatan kendaraan menggunakan metode support vector machine (tabel 2).

Table 2. Hasil klasifikasi SVM

\begin{tabular}{lcccccl}
\hline No & $\begin{array}{c}\text { Kec. } \\
(\mathbf{k m} / \\
\text { jam })\end{array}$ & $\begin{array}{c}\text { Jar } \\
\text { ak }\end{array}$ & $\begin{array}{c}\text { perio } \\
\text { da }\end{array}$ & $\begin{array}{c}\text { Peri- } \\
\text { ngatan }\end{array}$ & L1 & Hasil \\
\hline $\mathbf{1}$ & 43 & 24 & 0 & 1 & 0 & Aman \\
$\mathbf{2}$ & 40 & 12 & 0 & 1 & 1 & Bahaya \\
$\mathbf{3}$ & 34 & 30 & 0 & 1 & 1 & Bahaya \\
$\mathbf{4}$ & 63 & 23 & 0 & 1 & 1 & Bahaya \\
$\mathbf{5}$ & 60 & 24 & 0 & 1 & 1 & Bahaya \\
\hline
\end{tabular}

Tingkat akurasi menunjukkan seberapa baik sistem memprediksi suatu peristiwa. Metode yang digunakan untuk mendapatkan nilai akurasi data adalah validasi silang $\mathrm{k}$-fold. Berikut ini adalah tingkat akurasi sistem yang ditunjukkan pada tabel 3 .

Tabel 3. Akurasi SVM

\begin{tabular}{ccc}
\hline \multirow{2}{*}{ Jumlah } & \multicolumn{2}{c}{ Akurasi } \\
\cline { 2 - 3 } & $\begin{array}{c}\text { 1 folds }- \\
\text { Cross }\end{array}$ & $\begin{array}{c}10 \text { folds - } \\
\text { Cross }\end{array}$ \\
\hline $\mathbf{2 2 3 3}$ & $100 \%$ & $95.25 \%$
\end{tabular}

Ada 2 kali pengujian, yaitu 1 lipatan Cross Validation dan 10 lipatan - Cross Validation. Dengan 1 lipatan - Validasi Silang diperoleh nilai akurasi 100\%. Sedangkan dengan menggunakan 10 lipatan - Validasi Silang diperoleh nilai 95,25\% (tabel 3).

Berikut adalah beberapa hasil rekomendasi kecepatan yang diperoleh dengan metode logika fuzzy (tabel 4).

Tabel 4. Hasil Uji Fuzzy Logic

\begin{tabular}{cccc}
\hline $\begin{array}{c}\text { Kecepatan } \\
(\mathbf{k m} / \mathbf{j a m})\end{array}$ & $\begin{array}{c}\text { Jarak } \\
(\mathbf{m})\end{array}$ & $\begin{array}{c}\text { Rekemendasi } \\
\text { Kecepatan } \\
(\mathbf{k m} / \mathbf{j a m})\end{array}$ & Aksi \\
\hline $\mathbf{3 1}$ & 15 & 46,31 & Naikan \\
$\mathbf{3 2}$ & 20 & 45,00 & Naikan \\
$\mathbf{3 3}$ & 25 & 43,83 & Naikan \\
$\mathbf{3 4}$ & 30 & 39,00 & Naikan \\
$\mathbf{3 5}$ & 35 & 45,00 & Naikan \\
\hline
\end{tabular}

Berdasarakan tabel 4, jika kecepatan

$31 \mathrm{~km} / \mathrm{jam}$ dengan jarak kendaran di depan 15 meter maka kecepatan rekemendasi yang dihasilkan sitem $46.31 \mathrm{~km} / \mathrm{jam}$ dengan rekemendasi berupa suara dari sistem berupa "naikan Kecepatan".

\section{KESIMPULAN}

Hasil dari sistem yang telah dibuat dapat memberikan status keselamatan berkendaraan dan memberikan rekomendasi kecepatan, sistem juga dapat mengenali beberapa rambu lalu lintas serta memberikan peringatan rambu lalu lintas kepada pengemudi. Hasil klasifikasi akurasi keamanan kendaraan mencapai $95,25 \%$.

\section{UCAPAN TERIMA KASIH}

Ucapan terima kasih ditujukan kepada P3M Politeknik Negeri Indramayu.

\section{DAFTAR PUSTAKA}

Bengio, Y., P. Lamblin, D. Popovici, \& H. Larochelle. 2007. Greedy layer-wise training of deep networks. In Advances in neural information processing systems, 153-160.

Caragliu, A., C. Del Bo, \& P. Nijkamp. 2011. Smart cities in Europe. Journal of Urban Technology, 18(2): 65-82.

Gori, P., P.L. Parcu, \& M. Stasi. 2015. Smart cities and sharing economy. Robert Schuman Centre for Advanced Studies Research Paper No. RSCAS, 96.

Iranmanesh, S. M., H. Nourkhiz-Mahjoub, H. Kazemi \& Y.P. Fallah. 2018. An adaptive forward collision warning framework design based on driver distraction. IEEE Transactions on Intelligent Transportation Systems, 19(12), 3925-3934. DOI: 10.1109/TITS.2018.2791437.

Karpathy, A. 2017. Convolutional neural networks. Stanford.

Krizhevsky, A., I. Sutskever, \& G.E. Hinton. 2012. Imagenet classification with deep convolutional neural networks. In Advances in neural information processing systems, 1097-1105.

Mitchell, T. M., \& Others. 1997. Machine learning. McGraw-hill, New York. 
Mukhtar, A., L. Xia \& T.B. Tang. 2015. Vehicle detection techniques for collision avoidance systems: A review. IEEE Transactions on Intelligent Transportation Systems, 16(5): 23182338. DOI: $10.1109 /$ TITS.2015. 2409109.

Organization, W. H., \& Others. 2017. Road safety.

Park, H. S., D.J. Kim, C.M. Kang, S.C. Kee, \& C.C. Chung. 2017. Object detection in adaptive cruise control using multiclass support vector machine. 2017 IEEE 20th International Conference on Intelligent Transportation Systems (ITSC), 1-6.

Park, S., H. Han, B.S. Kim, J.H. Noh, J. Chi \& M.J. Choi. 2018. Real-Time Traffic Risk Detection Model Using Smart Mobile Device. Sensors (Basel, Switzerland), 18(11). DOI:10.3390/ s18113686.

Puspaningrum, A., A. Suheryadi \& A. Sumarudin. 2019. Pre-Collision Warning and Recommendation System for Assistant Driver using Least Square Support Vector Machine and Fuzzy Logic. 2019 International Seminar on Intelligent Technology and Its Applications (ISITIA), 371-375.
Rosyara, U. R., D. Vromman \& E. Duveiller. 2008. Fuzzy Sets. Journal of Plant Pathology, 90(1): 103-107. DOI:10.1016/S0019-9958(65)90241-X.

Saunders, T., P. Baeck \& Others. 2015. Rethinking smart cities from the ground up. Nesta, London.

Schölkopf, B. \& A.J. Smola. 2004. A tutorial on support vector regression. Statistics and Computing, 14(3):199-222. DOI:10.1023/B:STCO. 0000035301.49549.88.

Tian, Y., K. Pei, S. Jana \& B. Ray. 2018. Deeptest: Automated testing of deepneural-network-driven autonomous cars. Proceedings of the 40th international conference on software engineering, 303-314. 